\title{
Revealing active components, action targets and molecular mechanism of Gandi capsule for treating diabetic nephropathy based on network pharmacology strategy
}

\author{
Qiqiang Zhang ${ }^{1 \dagger}$, Qing Ye ${ }^{1 \dagger}$, Xiaohui Huang ${ }^{1+}$, Ajing Xu', Yan Liu' ${ }^{1}$ Jia Qi ${ }^{1}$, Hai Zhang ${ }^{2 *}$ and Jian Zhang ${ }^{1 *}$
}

\begin{abstract}
Background: Gandi capsule is a traditional Chinese herbal formula used to promote blood circulation and removing blood stasis in clinical. Our previous study has shown that it reduces proteinuria with routine treatment in diabetic nephrophy (DN), but its pharmacological action mechanism is still unknown.

Methods: To facilitate the identification of components, a component database of Gandi capsule and target database of DN were established by ourselves. The components absorbed in blood circle were identified in rat plasma after oral administration of Gandi capsule by UHPLC-QQQ-MS/MS. The potential targets were screened by using Libdock tolls in Discovery studio 3.0. Then Pathway and Network analyses were used to enrich the screened targets. The possible targets were verified by using a surface plasmon resonance (SPR) test and the molecular mechanism focusing these targets for treating DN was clarified by western blot.

Results: Six components in Gandi capsule were identified detected in rat plasma after oral administration by UHPLC-QQQ-MS/MS. After molecular docking analyses in KEGG and Discovery studio, four protein targets including HNF4A, HMGCR, JAK3, and SIRT1, were screened out, and proved as effective binding with baicalin, wogonoside by SPR. And the molecular mechanism was clarified that baicalin and wogonoside inhibit the effect of high glucose (HG)-induced decreased cell viability and podocin expression, and strengthen the activation p-AKT, p-PI3K, and pAMPK

Conclusion: Baicalin and wogonoside were screened out to be the active compounds in Gandi capsule and can ameliorate HG-induced podocyte damage by influencing the AMPK and PI3K-AKT signaling pathways by binding with HNF4A, HMGCR, JAK3, and SIRT1.
\end{abstract}

Keywords: Gandi capsule, Network pharmacology; active component UHPLC-QQQ-MS/MS, Surface plasmon resonance, Molecular mechanism; action target

\footnotetext{
*Correspondence: zhxdks2005@126.com; zhangjian@xinhuamed.com.cn

${ }^{\dagger}$ Qiqiang Zhang, Qing Ye and Xiaohui Huang contributed equally to this work.

${ }^{2}$ Department of Pharmacy, Shanghai First Maternity and Infant Hospital,

Tongji University School of Medicine, Shanghai 201204, China

'Department of Pharmacy, Xinhua Hospital, Affiliated to Shanghai Jiao Tong

University, School of Medicine, Shanghai 200092, China
}

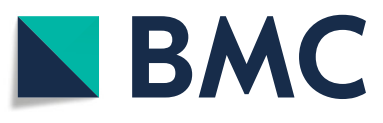

(c) The Author(s). 2020 Open Access This article is licensed under a Creative Commons Attribution 4.0 International License, which permits use, sharing, adaptation, distribution and reproduction in any medium or format, as long as you give appropriate credit to the original author(s) and the source, provide a link to the Creative Commons licence, and indicate if changes were made. The images or other third party material in this article are included in the article's Creative Commons licence, unless indicated otherwise in a credit line to the material. If material is not included in the article's Creative Commons licence and your intended use is not permitted by statutory regulation or exceeds the permitted use, you will need to obtain permission directly from the copyright holder. To view a copy of this licence, visit http://creativecommons.org/licenses/by/4.0/. The Creative Commons Public Domain Dedication waiver (http://creativecommons.org/publicdomain/zero/1.0/) applies to the data made available in this article, unless otherwise stated in a credit line to the data. 


\section{Background}

Diabetic nephropathy (DN) is a common diabetic complication that can lead to end-stage renal disease [1], also causes glomerulonephritis [2]. The morbidity and mortality related to DKD has rapidly increased over the past 20 years [3]. According to previous epidemiological data, DKD could be the primary cause for the progression to dialytic end-stage kidney diseases in the urban population in China [4]. The common clinical features of $\mathrm{DN}$ are proteinuria, progressive renal impairment, hypertension, and edema [5]. In clinic, hypoglycemic agents, lipid-lowering drugs, and anti-vasoactive drugs are the conventional medicines for DN [6]. Some of these drugs, including the sodium-dependent glucose transporter 2 (SGLT-2) inhibitor and angiotensinconverting enzyme inhibitor (ACEI), have been shown to treat proteinuria [7-9].

Gandi capsule (GDC) is derived from traditional Chinese medicine (TCM) prescription and used to promote blood circulation and assist the regular therapy of DN [10]. The GDC is composed of eight varieties of traditional Chinese herbs: Astragali Radix (Astragalus mongholicus Bunge., Huangqi), Corni Fructus (Cornus officinalis Siebold \& Zucc, Shanzhuyu), Rehmanniae Radix (Rehmannia glutinosa Gaertn., Dihuang), Leonuri Herba (Leonurus japonicus Houtt., Yimucao), Sophorae Flos (Styphnolobium japonicum (L.) Schott., Huaihua), Scutellariae Radix (Scutellaria baicalensis Georgi., Huangqin), Bombyx Batryticatus (Bombyx scindicus (Stocks) I.Riedl., Jiangcan), and phyllanthi fructus (Phyllanthus emblica L., Yuganzi) and full information of GDC is shown in Table S1. In our previous study, GDC reduced proteinuria in combination with routine medicinal therapy during a 4 month observation period [10]. Through metabonomic analysis on blood and urine of diabetes patients treated by GDC for 6 months, it was found that the levels of urinary albumin excretion was decreased and the levels of estimated glomerular filtration rate (eGFR) was increased after treatment of GDC [11]. Moreover, we have analyzed the compounds in GDC by UHPLC-QQQ-MS/MS in our previous research [12]. Considering the complex of components in GDC, research on the pharmacological mechanism of GDC is still a challenge. There is a urgent need to clarify the active components, action targets and molecular mechanism.

Network pharmacology is based on systems biology and uses bioinformatic methods [13]. It integrates the advantage of systems biology at the level of the organism, is applicable to the analysis of complex mixtures, and has been widely used for the analysis of TCMs [14], especially in drug discovery [15], synergistic pharmacology [16], and compatibility mechanism analysis [17]. In our previous study, we used surface plasmon resonance
(SPR) technology to discover the interactions of molecules and protein targets in vitro, which is a tool used to observe the interactions and dynamic changes between biological molecules. When a molecule binds to a protein on the surface of a medium, the refractive index of the medium will change, which can be transferred to an electrical signal. After the analysis of this signal, a series of parameters are displayed to evaluate the combination [18].

In this study, based on the clinical efficacy and component analysis of the Gandi capsule, a predicted analysis method was applied to screen active components and their potential targets via network pharmacology and structural biology, and further clarify the molecular mechanism. The results could provide a better understanding of the pharmacological mechanism of GDC in the treatment of $\mathrm{DN}$.

\section{Methods \\ Reagents and materials}

Gandi capsules was supplied by Fangxin Pharmaceutical Co., Ltd. (Shanghai, China). The batch number of Gandi capsules used are GD20190304 and manufacturing date is March, 16th, 2019. The standard powders, morroniside, loganin, baicalin, wogonoside, wogonin, and sweroside, were purchased from Nature Standard Co., Ltd. (Shanghai, China). Primary antibodies against rabbit podocin, phosphoinositide 3-kinase (PI3K), p-PI3K, protein kinase $\mathrm{B}(\mathrm{AKT}), \mathrm{p}-\mathrm{AKT}, 5^{\prime} \mathrm{AMP}$-activated protein kinase (AMPK) were from Abclone (Shanghai, China), and the dilutions were 1:1000. The primary antibodies against rabbit $\mathrm{p}$-AMPK was from Abcam (Cambridge, USA) and dilution was 1:2000. The anti-rabbit DyLight ${ }^{\text {TM }}$ 680 conjugated secondary antibodies from CST (Massachusetts, USA) and dilution was 1:1000. Hepatocyte nuclear factor 4-alpha (HNF4A), 3-hydroxy3-methylglutaryl-coenzyme A reductase (HMGCR), tyrosine-protein kinase Janus kinase 3 (JAK3), and NAD-dependent protein deacetylase sirtuin-1 (SIRT1) were obtained from Proteintech Co., Ltd. (Chicago, America). Recombinant interferon gamma was from Sigma (Aldrich, USA). CCK-8 Kit was from YEASEN (Shanghai, China). Radioimmunoprecipitation assay lysis buffer and Bicinchoninic acid protein assay kit were from Beyotime (Shanghai, China). Nitrocellulose membrane was from Pall Co., Ltd. (New York, USA).

\section{Experimental animals}

All experimental procedures complied with the Guidelines on the Care and Use of Laboratory Animals (National Institutes of Health Publication no.85-23, revised 1996) and were approved by the Institutional Animal Care and Use Committee of the Shanghai Jiaotong University, School of Medicine [Shanghai, China, NO. SYXK 
(Shanghai) 2018-0038], and authorized by Xinhua Hospital, affiliated to Shanghai Jiao Tong University, School of Medicine (Shanghai 200,092, China). Male sprague Dawley (SD) rats at 10 weeks old, weighing $180-220 \mathrm{~g}$, were supplied by Shanghai SLAC Laboratory Animal Co.,Ltd. (Shanghai, China).

All animals were fed in a SPF environment in the Laboratory Animal Center of Xinhua Hospital affiliated to Shanghai Jiaotong University School of Medicine maintained at the temperature of $25 \pm 2{ }^{\circ} \mathrm{C}$ and relative humidity of $45 \pm 5 \%$ and provided with water and food freely.

\section{Establishment of component database and target protein database}

According to the composition of the Gandi capsule, we built a compound database with 136 components using a Traditional Chinese Medicine and Active Ingredient Database (http://www.organchem.csdb.cn/). After analyzing the oral bioavailability $(\mathrm{OB})$ and drug-likeness (DL) in the traditional Chinese medicine systems pharmacology online database (http://lsp.nwu.edu.cn/). Filter parameters were $\mathrm{OB}>30 \%$ and $\mathrm{DL}>0.18$. Finally, 97 components were considered for this study.

We also founded a Target Protein Database to contain the protein targets related to $\mathrm{DN}$. These targets are divided into two parts: confirmed targets and predicted targets. Confirmed targets are from the online databases the Therapeutic Target Database (TTD) (http://bidd.nus. edu.sg/group/cjttd/) and DisGeNET (http://www.disgenet.org/) by searching the keyword "diabetic nephropathy". Predicted targets came from microarray data GSE30528, which includes 9 DN samples and 13 diabetes mellitus samples. This data is from the Gene Expression Omnibus (GEO) database (https://www.ncbi. nlm.nih.gov/geo/). To select more accurate targets, we set the filter parameter to $P \leq 0.05$ and log fold change $(\operatorname{logFC})$ (differential multiple) $\geq 2$ or $\log \mathrm{FC} \leq-2$. Finally, we synthesized two different targets for diabetes mellitus from the target protein database.

\section{Analysis of components absorbed in blood by UHPLC- QQQ-MS/MS}

Before experiment, rats were fasted $12 \mathrm{~h}$ before experiment and water was taken freely. And then the contents of the GDC were made into a suspensions with sterile water-5\%Tween 80 .Total 12 rats were administered with $0.27 \mathrm{~g}$ of drug suspensions per $1 \mathrm{~kg}$ of bodyweight or sterile water randomly by way of stomach, each group had six samples. This dose was identified based on the clinic dosage $(0.3 \mathrm{~g} /$ per capsule* 3 capsules/per time* 3 times/ per day) of GDC in patients weighting $60 \mathrm{~kg}$. And according to the result of pre-expreiment, $2 \mathrm{~h}$ later, after all rats receving $\mathrm{CO}_{2}$ gently and sacrificing, blood samples were collected by heart exposing and punctures. Then the addition of $500 \mu \mathrm{L}$ of acetonitrile and $10 \mu \mathrm{L}$ of internal standard per $90 \mu \mathrm{L}$, the mixture was vortexed for $30 \mathrm{~s}$ and centrifuged at 13,000 rpm for $4 \mathrm{~min}$. Only the supernatant was used. The standard powders, morroniside, loganin, baicalin, wogonoside, wogonin, and sweroside, were purchased from Nature Standard Co., Ltd. (Shanghai, China). Every drug powder was high purity ( $\geq 98 \%$ ). The standard samples were added to a blank sample and operated by the same process as the capsule treated rats. The concentration of each standard compound in the mixture was $500 \mathrm{ng} / \mathrm{mL}$.

To accurately identify the compounds, we compared the samples with standards via UHPLC-QQQ-MS/MS, which consisted of a Waters UPLC system with an Applied Biosystem 5500 QTRAP $^{\circ}$ hybrid triple-quadrupole mass spectrometer (Applied Biosystems/MDS Sciex, Foster City, CA, USA). This system was equipped with a turbo ion spray source. Chromatographic separation was performed on a ZORBAX Eclipse Plus C18 (50 $\mathrm{mm} \times$ $2.1 \mathrm{~mm}, 1.8 \mu \mathrm{m})$. The mobile phase consisted of (A) $0.1 \%$ formic acid-deionized water and (B) acetonitrile. The autosampler tray was maintained at $20^{\circ} \mathrm{C}$ and the column at $50{ }^{\circ} \mathrm{C}$. The following gradient elutions were used: $0.0-3.0 \mathrm{~min}, 30.0 \rightarrow 74.0 \% \mathrm{~B}$; $3.0-3.1 \mathrm{~min}, 74.0 \rightarrow$ 95.0\% B; 3.1-4.6 min, 95\% B; 4.6-4.7 min, $95.0 \rightarrow 30 \%$ B; and $4.7-7.0 \mathrm{~min}, 30 \% \mathrm{~B}$.

Nitrogen was used in four different ways: the curtain (CUR) gas, nebulizer (GS1), heater (GS2), and the collision activation dissociation (CAD) gas. Firstly, all targeted analytes were tested in the multiple reaction monitoring (MRM) acquisition mode by MS/MS for simultaneous detection and two precursor-to-product ion transitions were monitored for the two compounds. Then, all source settings and instrument parameters for each MRM transition were optimized for the generation of as much protonated analyte molecules $\left([\mathrm{M}+\mathrm{H}]^{+}\right)$as possible for each targeted compound to efficiently produce its characteristic fragment/product ions. The ion spray needle voltage was set at $5500 \mathrm{~V}$ and the source temperature was $550^{\circ} \mathrm{C}$.

The following setting parameters were optimized; electrospray ionization source was operated with the CUR, GS1, and GS2 set at 40, 35, and 35 psi, respectively; independent precursor-product ion transitions specific to each analyte that depended on the instrumental parameters of the compound, such as the precursor ion, two product ions, declustering potential (DP), entrance potential (EP), collision energy (CE), and collision cell exit potentials (CXP); and the parameters were $50 \mathrm{~V}, 19 \mathrm{eV}, 10 \mathrm{~V}$, and 12 successively for the lactones. To detect osthol, the transition from precursor ion $[\mathrm{M}+\mathrm{H}]^{+}$at $\mathrm{m} / \mathrm{z} 233.2$ to product ion at $\mathrm{m} / \mathrm{z} 187.1$ was monitored. As the transition from 
the precursor was $\mathrm{m} / \mathrm{z} 245.1$ to the product at $\mathrm{m} / \mathrm{z}$ 189.1, the dwell time was set at $550 \mathrm{~ms}$.

\section{Molecular docking}

To establish the correlation between drug molecules and targets, we used the docking software in Discovery Studio 3.0. Firstly, all target names were standardized using the data from the Uniprot database (https://www.uniprot.org/). Then, by selecting the minimum value from each resolution, a parameter used to describe the difference between the real and virtual target structures, the best target structures were obtained. All target structures were crystal structures determined by X-ray. This provided another filter for our study. A total of 373 protein targets and their structures were imported into Discovery Studio 3.0. After initial preparation, all structures were optimized by hydrogenation, water removal, or structural simplification. The canonical simplified molecular-input line-entry system data were imported into the software to build the molecular structures. Finally, every molecule was docked with the targets above to acquire the docking parameter $\mathrm{X}_{\text {libdockscore. In }}$ addition, the ligand of each target was docked to acquire the parameter $\mathrm{X}_{\text {ligand }}$. All operations were performed under the CHARMM force field.

\section{Kyoto encyclopedia of genes and genomes (KEGG) enrichment analysis}

To reduce the false-positive result of docking, two calculation formulas were applied. One was " $\mathrm{D}$-value $=\mathrm{X}_{\text {lib- }}$ dockscore - $\mathrm{X}_{\text {ligand }}$ and $\mathrm{D}$-value $\geq 0$ ", which was applied to confirm the differential binding affinity of molecules with targets compared to that with the ligand. The other was " ${ }^{\text {- }} \mathrm{X}_{\text {libdockscore }}=\Sigma\left(\mathrm{X}_{\text {libdockscore }}\right) /$ (number of targets) and $\mathrm{X}_{\text {libdockscore }} \geq^{-} \mathrm{X}_{\text {libdockscore". This formula filtered the }}$ term near the critical value. A calculation was performed for every molecule. After analyzing the docking data, all targets were subjected to KEGG enrichment analysis. This step was achieved using the online analysis website David (https://david.ncifcrf.gov/). We acquired enrichment pathways easily using the Function Annotation module. All enriched pathways were displayed in turn by comparing the $P$ values.

\section{Network building and analysis}

To establish the connection of molecules, targets, and pathways all selected terms were imported into Cytoscape 3.7 based on the results of molecular docking and KEGG enrichment analysis. Following the network analysis, an attached software analysis module was applied. Afterward, the parameter "Neighborhood Connectivity" (NC) was applied. As for the targets and pathways, if their NC was more than that of others, it was considered to be more enriched.

\section{Target validation by SPR assay}

To verify the effectiveness of the above method, 11 representational molecule-target pairs were chosen for the SPR test. We installed 3 regulars to choose these 11 molecule-target pairs. The first one was 'greater value of "Neighborhood Connectivity". The second one was 'greater value of " $\mathrm{X}_{\text {libdockscore"'. The last one was 'target }}$ that docked with more molecules'. In the SPR test, the solution of protein standards was prepared and the concentration of the protein solution was $500 \mu \mathrm{g} / \mathrm{mL}$. After combining with chips, a series of concentrations of compounds, which were double diluted step to step, were tested for their binding affinity to the proteins. Finally, the binding level between the protein and molecule was determined by the parameter $\mathrm{Kd}$ value.

\section{Cell line and cell culture}

Human podocyte cell line was obtained from XYBiotechnology (Shanghai, China) and was cultured as previous research [19]. Briefly, cells were cultured in a Roswell Park Memorial Institute (RPMI) 1640 medium (Hyclone, Shanghai, China) mixed with 10\% fetal bovine serum (FBS) and $1 \%$ penicillin-streptomycin at $5 \% \mathrm{CO}_{2}$ and $37^{\circ} \mathrm{C}$. Before the experimental operation, the cells were cultured in RPMI 1640 medium supplemented with $10 \mathrm{U} / \mathrm{mL}$ recombinant interferon gamma at $33^{\circ} \mathrm{C}$ for 2 weeks after seeding in culture plates. Only the differentiated cells were used in our research.

\section{Cell counting kit-8 (CCK-8) assay}

Cells were shifted to a 96-well plate at a density of $1 \times$ $10^{5} /$ well. Afterwards, the cells were treated with a series of baicalin concentrations $(0,2.5,5,10,12.5,25,50,75$, and $100 \mathrm{mg} / \mathrm{L})$ and wogonoside (0, 2.5, 5, 10, 12.5, 25, 50 , and $100 \mathrm{mg} / \mathrm{L})$. After approximately $48 \mathrm{~h}$, the samples were assayed with CCK-8 at $450 \mathrm{~nm}$ to find a maximum safe concentration for podocyte cells. Later, in another 96-well plate, cells were exposed to a high glucose condition (HG, $30 \mathrm{mM}$ D-glucose), normal glucose condition (Control, $5 \mathrm{mM}$ D-glucose), mannitol (MA, 5 $\mathrm{mM}$ D-glucose $+25 \mathrm{mM}$ mannitol), dimethyl sulfoxide (DMSO, < $0.5 \%$ ), baicalin (5 or $10 \mathrm{mg} / \mathrm{L}$ ), and wogonoside (5 or $10 \mathrm{mg} / \mathrm{L}$ ). This was also assayed with CCK-8 solution at $450 \mathrm{~nm}$ after $48 \mathrm{~h}$.

\section{Western blot analyses}

After incubation with the indicated conditions, the cells were washed twice with $1 \times$ phosphate-buffered saline and lysed with radioimmunoprecipitation assay lysis buffer. After vortexing $15 \mathrm{~s}$ and centrifugation in 14,000 g, the extracted protein content was detected using a bicinchoninic acid protein assay kit. Afterward, various groups of protein were electrophoresed using 10\% sodium dodecyl sulfate-polyacrylamide gel electrophoresis 
and transferred onto a nitrocellulose membrane via electroblotting. To prevent non-specific binding, the membrane was blocked with $5 \%$ non-fat milk dissolved in $1 \times$ Tris-buffered saline and $0.1 \%$ Tween 20 . Then, the membranes were incubated with primary antibodies against rabbit podocin, PI3K, p-PI3K, AKT, p-AKT, AMPK, and p-AMPK at $4{ }^{\circ} \mathrm{C}$ overnight. The membrane was then washed with $1 \times$ TBST three times and incubated with DyLight ${ }^{\mathrm{Tm}} 680$ conjugated secondary antibodies (CST, Massachusetts, USA) for $1 \mathrm{~h}$. Finally, after washing three times with $1 \times \mathrm{TBST}$, the membrane was scanned.

\section{Statistical analysis}

All experiments were repeated for three times. Statistical analysis was conducted using GraphPad Prism 7.0 software (La Jolla, CA, USA). The Student's t test was used to examine the differences between two groups. Differences were considered significant if $P<0.05$.

\section{Results}

Construction of molecule database and protein database There were 97 components in the filtered molecule database (shown in Table S2). After comparison with 52 ingredients in Gandi capsules in vitro which we detected before [12], only 12 potential components were used, as shown in Table 1. As for predicted targets, there were 119 genes that changed after filtration, which means that these protein targets might be related to DN. The differential expression of these genes is shown in Fig. 1a. Additionally, there were 209 confirmed targets in TTD and 724 in Disgenet. After removing duplicates, there were 918 targets in the target protein database and the source constitution of the target protein database is shown in Fig. 1b.

\section{Identification of components absorbed into blood circle via UHPLC-QQQ-MS/MS}

Both positive and negative ion detection modes responded well in quadrupole full scans by a $100 \mathrm{ng} / \mathrm{mL}$ tuning solution in methanol, which was achieved in positive ionization mode for isoalantolactone, alantolacton. The protonated molecular ions revealed peaks of morroniside, loganin, baicalin, wogonoside, wogonin, sweroside and internal standard (IS) at $\mathrm{m} / \mathrm{z} 451.0,408.2$, 445.1, 461.1, 285.1, 357.1 and 245 respectively. Most abundant ions were produced by the target protonated molecular ions, and morroniside was observed in [M$\mathrm{HCOO}]^{-}$ions at $\mathrm{m} / \mathrm{z}$ 179.0; loganin was in $\left[\mathrm{M}+\mathrm{NH}_{4}\right]^{+}$ at $\mathrm{m} / \mathrm{z}$ 229.0; baicalin was in $[\mathrm{M}+\mathrm{H}]^{-}$at $\mathrm{m} / \mathrm{z} 269.0$; wogonoside and wogonin was in $[\mathrm{M}+\mathrm{H}]^{+}$at $\mathrm{m} / \mathrm{z} 283.0$ and 270.0 respectively; sweroside was in $[\mathrm{M}-\mathrm{H}]^{-}$at $\mathrm{m} / \mathrm{z}$ 125.0. The mobile phase, types of chromatography columns, and column temperatures were tested to optimize the chromatographic conditions.

An acetonitrile-water mobile phase system from 30 to $95 \%$ acetonitrile without any acid in $3.10 \mathrm{~min}$ was applied because it can enhance the mass spectrum response of isoalantolactone and alantolactone. Zorbax Eclipse Plus-C18 $(2.1 \times 50 \mathrm{~mm}, 1.8 \mu \mathrm{m})$ analytical column was selected to produce more satisfactory chromatography results than other commercially available $\mathrm{C} 18$ columns, such as Poroshell 120EC-C18 $(3.0 \times 50 \mathrm{~mm}$, $2.7 \mu \mathrm{m})$ and Acquity UPLC BEH C18 $(2.1 \times 50 \mathrm{~mm}$, $1.7 \mu \mathrm{m})$. Three column temperatures $\left(30^{\circ} \mathrm{C}, 40^{\circ} \mathrm{C}\right.$, and $50^{\circ} \mathrm{C}$ ) were tested and $50^{\circ} \mathrm{C}$ was selected as it had the shortest retention time. Based on the above analysis, morroniside, loganin, baicalin, wogonoside, wogonin, sweroside were eluted at retention times of 3.106, 3.407, 4.592, 5.100, 6.300, and $3.490 \mathrm{~min}$, respectively, and IS was eluted at $2.60 \mathrm{~min}$. The parameters of target ions were set at $\mathrm{m} / \mathrm{z} 451.0 \rightarrow 179.0$ for morroniside, $\mathrm{m} / \mathrm{z}$ $408.2 \rightarrow 229.0$ for loganin, $\mathrm{m} / \mathrm{z} \quad 445.1 \rightarrow 269.0$ for

Table 1 Information of 12 potential components

\begin{tabular}{llllll}
\hline NO. & Molecule Name & Formula & MW & Mol ID & Origin \\
\hline 1 & formononetin & $\mathrm{C}_{16} \mathrm{H}_{12} \mathrm{O}_{4}$ & 268.28 & MOL000392 & Astragali Radix \\
2 & isorhamnetin & $\mathrm{C}_{16} \mathrm{H}_{12} \mathrm{O}_{7}$ & 316.28 & MOL000354 & Astragali Radix \\
3 & kaempferol & $\mathrm{C}_{15} \mathrm{H}_{10} \mathrm{O}_{6}$ & 286.25 & MOL000422 & Astragali Radix \\
4 & $\mathrm{C}_{15} \mathrm{H}_{10} \mathrm{O}_{7}$ & 302.25 & MOL000098 & Astragali Radix \\
5 & quercetin & $\mathrm{C}_{14} \mathrm{H}_{6} \mathrm{O}_{8}$ & 302.20 & MOL001002 & Phyllanthi fructus \\
6 & ellagic acid & $\mathrm{C}_{14} \mathrm{H}_{9} \mathrm{O}_{9}$ & 321.21 & MOL000569 & Phyllanthi fructus \\
7 & digallate & $\mathrm{C}_{17} \mathrm{H}_{26} \mathrm{O}_{10}$ & 390.43 & MOL001680 & Corni Fructus \\
8 & loganin & $\mathrm{C}_{17} \mathrm{H}_{26} \mathrm{O}_{11}$ & 406.38 & MOL001683 & Corni Fructus \\
9 & morroniside & $\mathrm{C}_{16} \mathrm{H}_{22} \mathrm{O}_{9}$ & 358.38 & MOL000650 & Corni Fructus \\
10 & sweroside & $\mathrm{C}_{21} \mathrm{H}_{18} \mathrm{O}_{11}$ & 446.39 & MOL002776 & Astragali Radix \\
11 & baicalin & $\mathrm{C}_{22} \mathrm{H}_{20} \mathrm{O}_{11}$ & 460.40 & MOL013068 & Scutellariae Radix \\
12 & wogonoside & $\mathrm{C}_{16} \mathrm{H}_{12} \mathrm{O}_{5}$ & 284.28 & MOL000173 & Scutellariae Radix \\
\hline
\end{tabular}




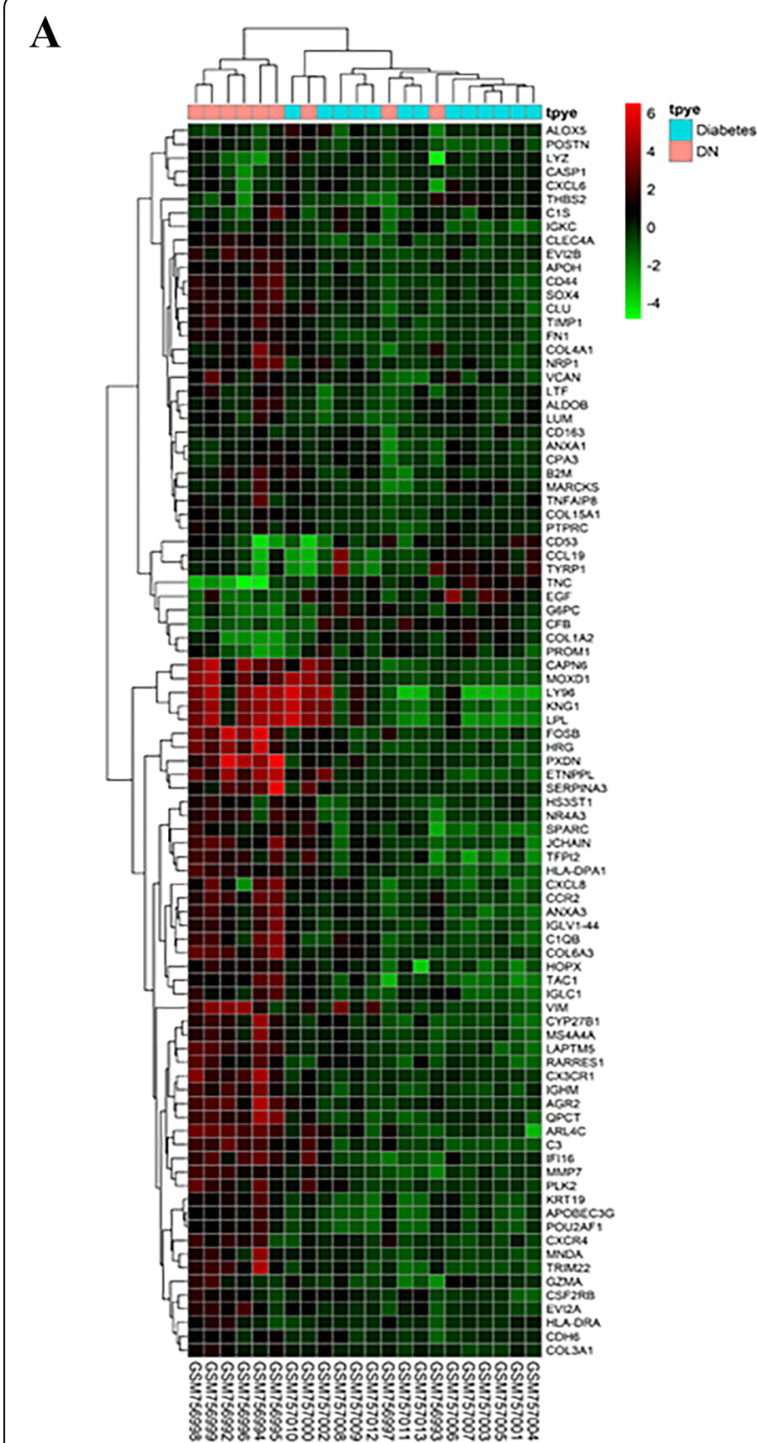

B

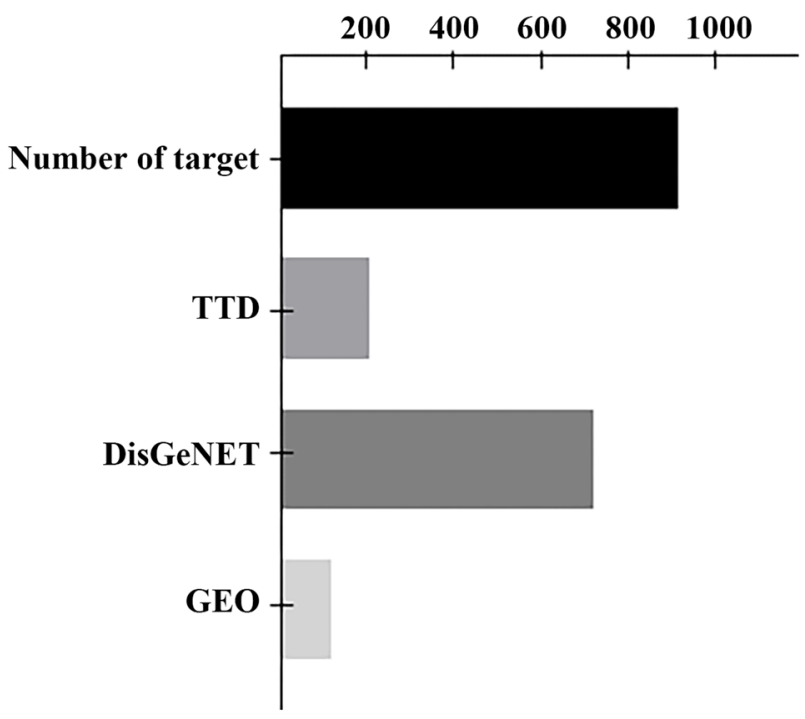

Fig. 1 The molecular and protein databases. a Heatmap of microarray data "GSE30528". The filter parameter is " $p \leq 0.05$ and logFC $\geq 2$ or logFC $\leq-2$ ". $\mathbf{b}$ The source constitution of the protein target database. TTD targets are from the online database "http://bidd.nus.edu.sg/group/cjttd/" and DisGeNET is from "http://www.disgenet.org/". Moreover, the target using the term "GEObase" is from microarray data GSE30528

baicalin, $\mathrm{m} / \mathrm{z} \quad 461.1 \rightarrow 283.0$ for wogonoside, $\mathrm{m} / \mathrm{z}$ $285.1 \rightarrow 270.0$ for wogonin, $\mathrm{m} / \mathrm{z} \quad 357.1 \rightarrow 125.0$ for sweroside and $\mathrm{m} / \mathrm{z} 245.1 \rightarrow 189.1$ for $I S$ in the MRM mode for UHPLC-QQQ-MS/MS.

After the analysis of the sample, six representational molecules, morroniside, loganin, baicalin, wogonoside, wogonin, and sweroside, were selected. The total ion chromatograms for the compounds are shown in Fig. $2 \mathrm{a}-\mathrm{d}$ and their information is in Table 2.

\section{Virtual docking and compound-target-pathway network analysis}

Molecular docking, KEGG enrichment analysis, and network analysis were applied. Molecular docking was a high-through method and a first filter tool for our study.
In total, 373 targets were docked with 6 compounds after X-ray structures were filtered. After 2238 docking experiments, we acquired 748 positive results of molecule-target pairs, including 141 with morroniside, 141 with loganin, 163 with baicalin, 114 with wogonoside, 54 with wogonin, and 135 with sweroside. In virtual docking, molecules bound to targets via a series of interactive forces, such as hydrogen bonds, van der Waals forces, and conjugated bonds. The docking statistical results are shown in Fig. 3a-c. These targets were filtered in the form of molecular-target pairs, then 131 targets were used in KEGG enrichment analysis. After analysis and classification, 30 pathways entered the next step as potential active pathways. These enrichment pathways are shown in Fig. 3d. 

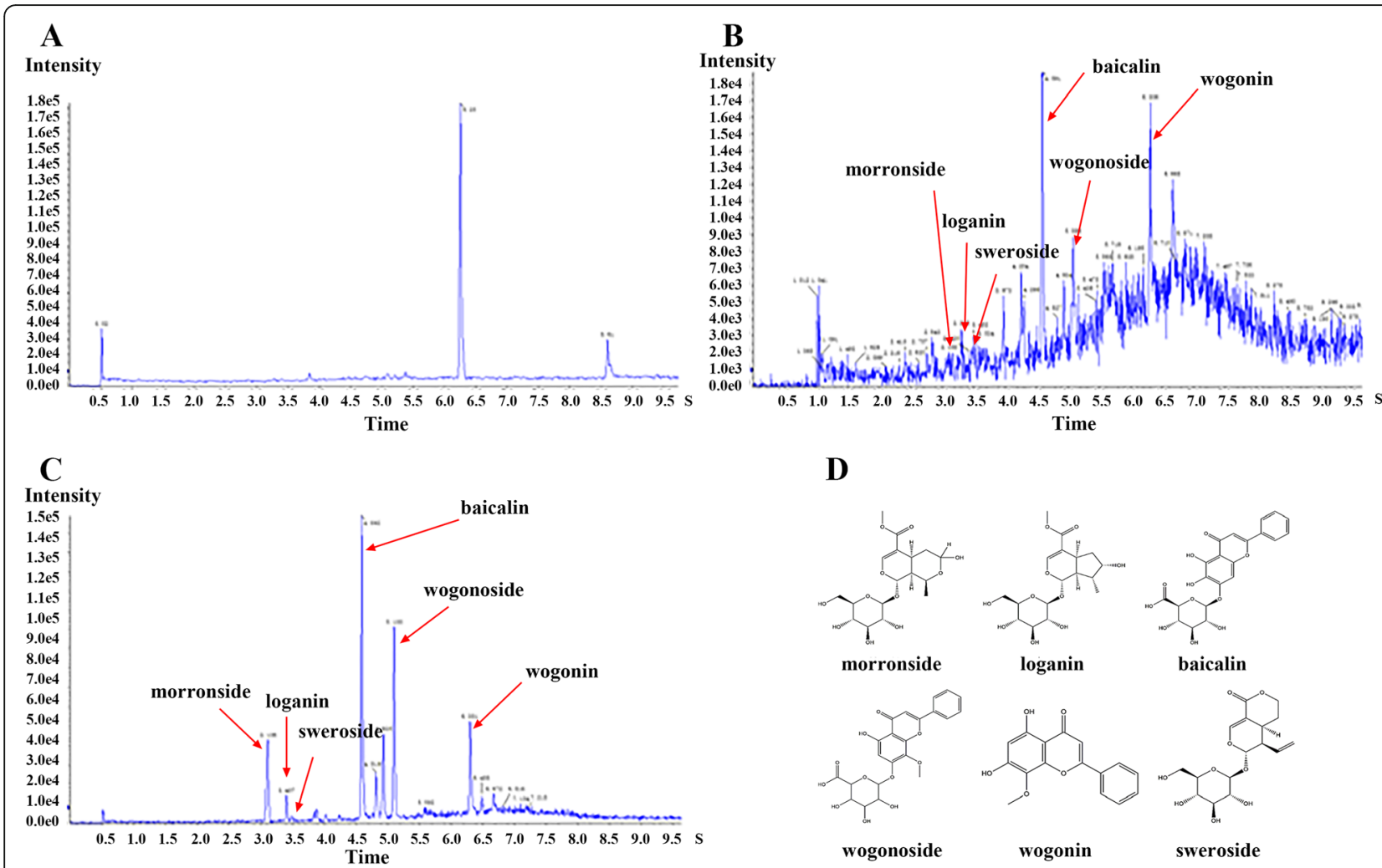

D

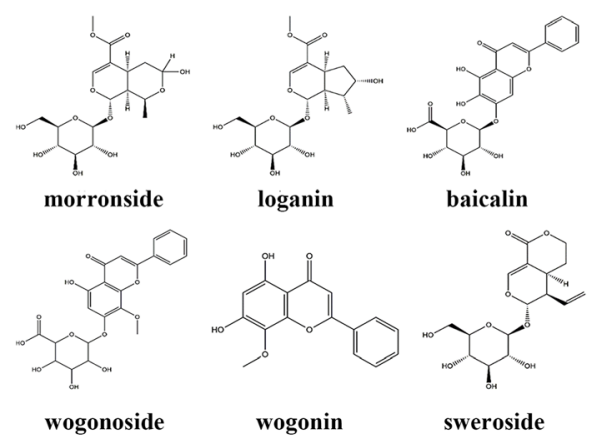

Fig. 2 Ion flow diagram of UHPLC-QQQ-MS/MS. a Blank plasma b Plasma sample from rat after oral administration with Gandi capsule (12 g/kg) for $2 \mathrm{~h}$ c Standard mixture $\mathbf{d}$ Six potential compounds' structures

By analyzing the representative pathways and targets under each term, a relationship of compound-targetpathway is displayed in a network shown in Fig. 3e. In this network, 97 nodes are marked, including 6 compounds, 61 target proteins, and 30 pathways. HNF4A, HMGCR, JAK3, and SIRT1 were outstanding according to the parameter "Neighborhood Connectivity".

\section{Verification of the binding relationship of baicalin and wogonoside via SPR}

In total, 11 compound-target pairs were enrolled in the SPR test and they were shown in Table 3, including SIRT1 with morroniside, loganin, baicalin, wogonoside, and sweroside; HMGCR with baicalin and wogonoside; HNF4A with baicalin and wogonoside; and JAK3 with baicalin and wogonoside. Eight compound-target pairs, including baicalin and wogonoside with HNF4A, HMGCR, JAK3, and SIRT1, interacted with each other in vitro. All positive binding results are shown in Fig. $4 \mathrm{a}$ to $\mathrm{h}$ and the information and parameters of this result are shown in Table 4. Based on the result of SPR and KEGG enrichment analysis, we discovered that these four targets were clustered in the PI3KAKT and AMPK signaling pathways. Baicalin and wogonoside were the most significantly compounds in our study.

Table 2 Mass spectrometry of six representational compounds

\begin{tabular}{llllllll}
\hline ID & Compounds & Formula & Molecular Weight $\left(\mathbf{g} \cdot \mathbf{m o l}^{\mathbf{- 1}} \mathbf{)}\right.$ & $\begin{array}{l}\text { Retention Time } \\
\text { t/min }\end{array}$ & Parent ion $(\mathbf{m} / \mathbf{z})$ & Product ion $(\mathbf{m} / \mathbf{z})$ & Ionization mode \\
\hline 1 & morroniside & $\mathrm{C}_{17} \mathrm{H}_{26} \mathrm{O}_{11}$ & 406.380 & 3.106 & 451.000 & 179.000 & {$[\mathrm{M}-\mathrm{HCOO}]^{-}$} \\
2 & loganin & $\mathrm{C}_{17} \mathrm{H}_{26} \mathrm{O}_{10}$ & 390.430 & 3.407 & 408.200 & 229.000 & {$[\mathrm{M}+\mathrm{NH}]^{+}$} \\
3 & baicalin & $\mathrm{C}_{21} \mathrm{H}_{18} \mathrm{O}_{11}$ & 446.360 & 4.592 & 445.100 & 269.000 & {$[\mathrm{M}+\mathrm{H}]^{-}$} \\
4 & wogonoside & $\mathrm{C}_{22} \mathrm{H}_{20} \mathrm{O}_{11}$ & 460.390 & 5.100 & 461.100 & 283.000 & {$[\mathrm{M}+\mathrm{H}]^{+}$} \\
5 & wogonin & $\mathrm{C}_{16} \mathrm{H}_{12} \mathrm{O}_{5}$ & 284.300 & 6.300 & 285.100 & 270.000 & {$[\mathrm{M}+\mathrm{H}]^{+}$} \\
6 & sweroside & $\mathrm{C}_{16} \mathrm{H}_{22} \mathrm{O}_{9}$ & 358.340 & 3.490 & 357.100 & 125.000 & {$[\mathrm{M}-\mathrm{H}]^{-}$} \\
\hline
\end{tabular}




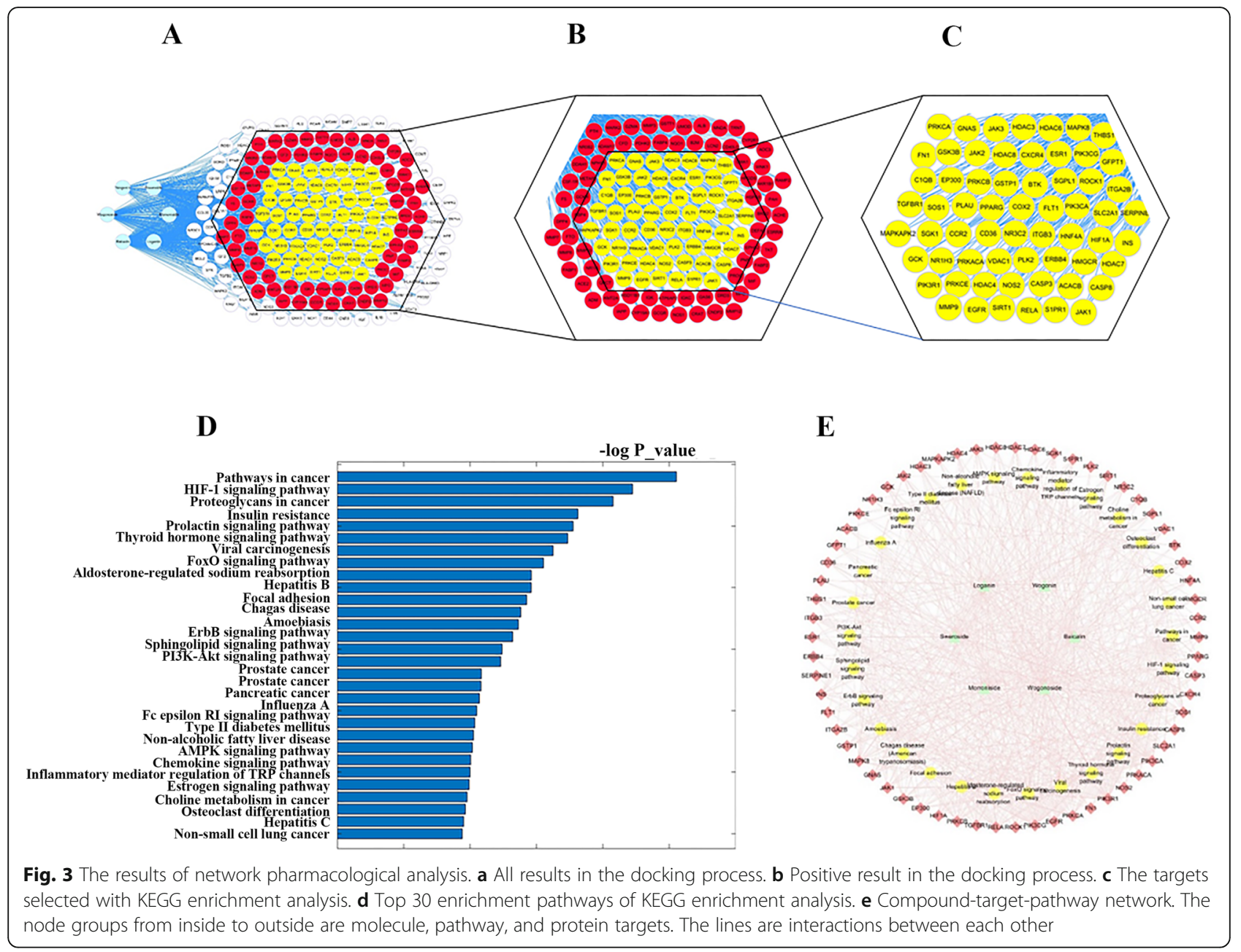

Baicalin and wogonoside enhanced cell viability in the HG condition in human podocyte cells

To discover the influence of these compounds, we investigated the cytotoxicity of baicalin and wogonoside and discovered that they had little cytotoxicity to human podocytes at concentrations below $10 \mathrm{mg} / \mathrm{L}$. This is shown in Fig. 5a and b. Furthermore, pretreating with baicalin and wogonoside at different doses offset the effect of HG on cell viability. The result suggested that HG induced the decreased cell viability; however, baicalin and wogonoside reduced this influence on human podocyte cells, as shown in Fig. 5c. We also verified this hypothesis using podocin, a marker of $\mathrm{DN}$ via western blotting, as shown in Fig. 5d, e.

\section{Baicalin and wogonoside altered the phosphorylation and expression of AMPK, PI3K, and AKT in the HG condition in human podocyte cells}

To verified influence of baicalin and wogonoside in PI3K-AKT pathway and AMPK pathway in cells, we

Table 3 Notable targets after network analysis

\begin{tabular}{|c|c|c|c|c|}
\hline $\begin{array}{l}\text { Share } \\
\text { Name }\end{array}$ & Common Name & $\begin{array}{l}\text { PDB } \\
\text { Code }\end{array}$ & Binding Molecule & Related pathway \\
\hline HMGCR & $\begin{array}{l}\text { 3-hydroxy-3-methylglutaryl-coenzyme A } \\
\text { reductase }\end{array}$ & 1DQ8 & baicalin; wogonoside & AMPK signaling pathway \\
\hline HNF4A & Hepatocyte nuclear factor 4-alpha & $3 F S 1$ & baicalin; wogonoside & AMPK signaling pathway \\
\hline SIRT1 & NAD-dependent protein deacetylase sirtuin-1 & $4 Z Z I$ & $\begin{array}{l}\text { morroniside; loganin; baicalin; wogonoside; } \\
\text { sweroside }\end{array}$ & AMPK signaling pathway \\
\hline JAK3 & Tyrosine-protein kinase Janus kinase 3 & $3 L X L$ & baicalin; wogonoside & $\begin{array}{l}\text { PI3K-Akt signaling } \\
\text { pathway }\end{array}$ \\
\hline
\end{tabular}



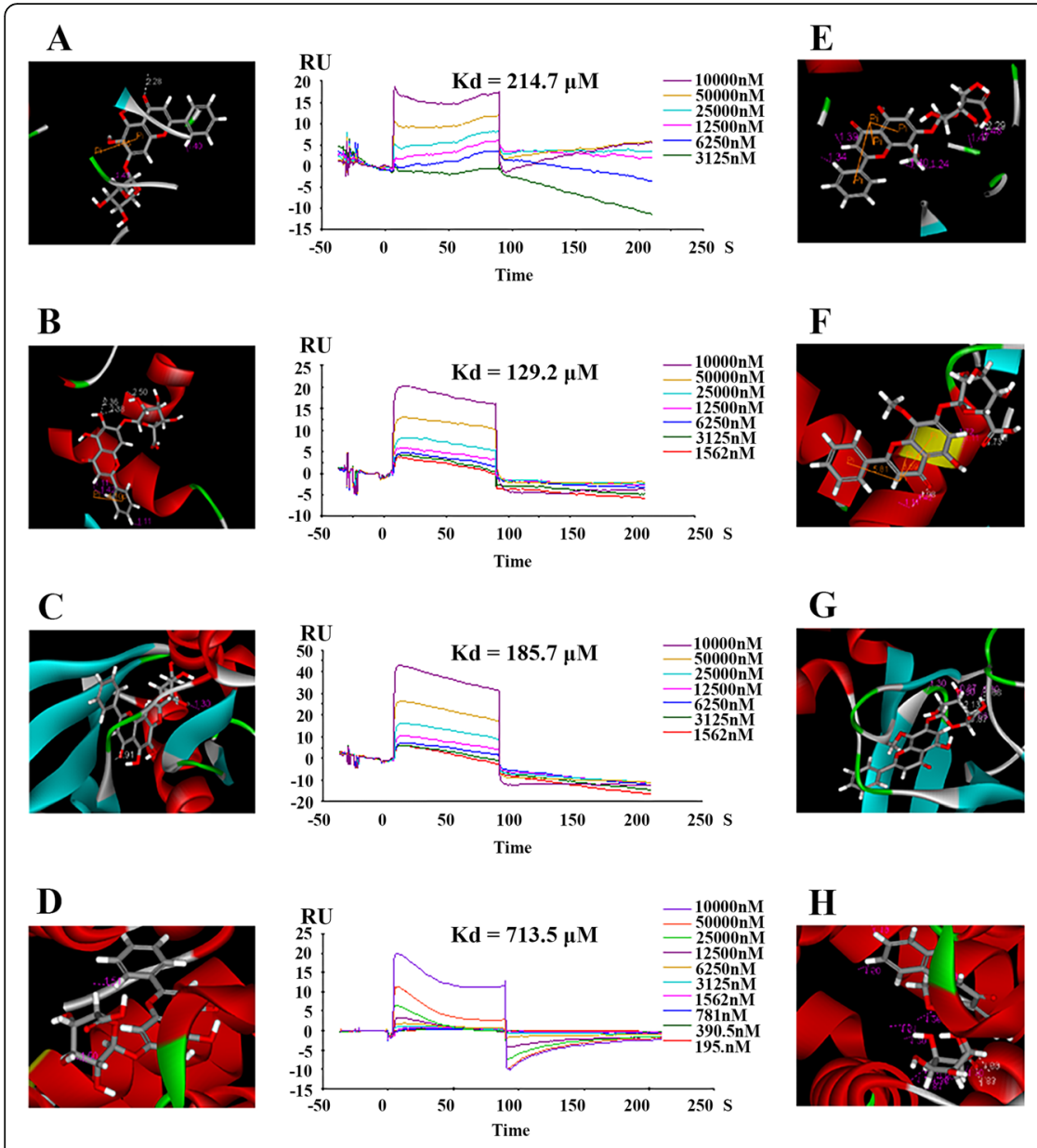
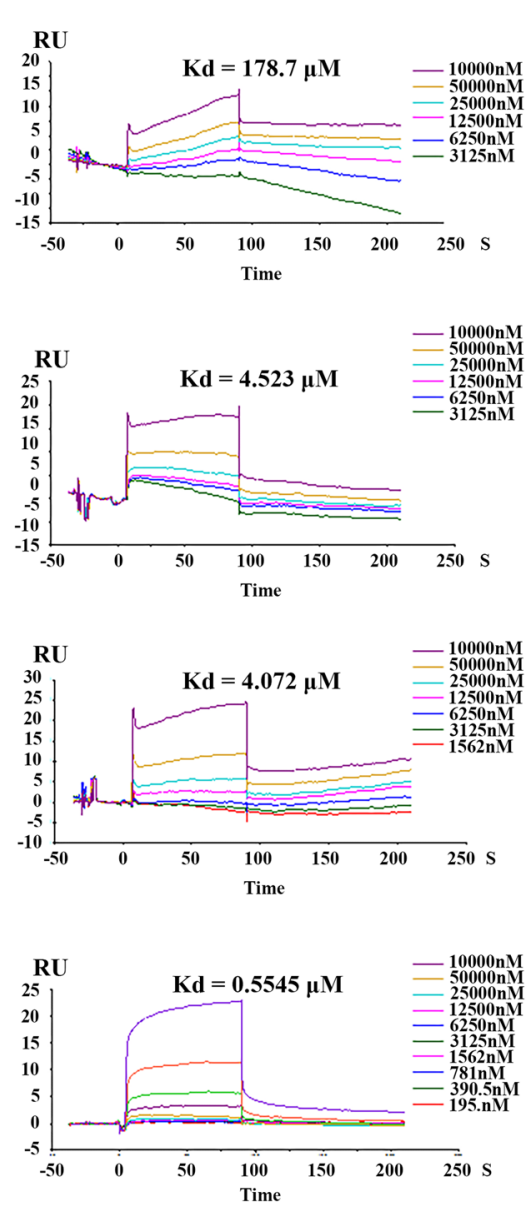

Fig. 4 Binding diagram of eight representational molecule-target pairs. The left one in each group is the schematic drawing of virtual docking and the right is surface plasmon resonance (SPR) result. a NAD-dependent protein deacetylase sirtuin-1 (SIRT1) and baicalin. b 3-hydroxy-3methylglutaryl-coenzyme A reductase (HMGCR) and baicalin. c Tyrosine-protein kinase Janus kinase 3 (JAK3) and baicalin. $\mathbf{d}$ Hepatocyte nuclear factor 4-alpha (HNF4A) and baicalin. e NAD-dependent protein deacetylase sirtuin-1 (SIRT1) and wogonoside. f 3-hydroxy-3-methylglutarylcoenzyme A reductase (HMGCR) and wogonoside. $\mathbf{g}$ Tyrosine-protein kinase Janus kinase 3 (JAK3) and wogonoside. $\mathbf{h}$ Hepatocyte nuclear factor 4-alpha (HNF4A) and wogonoside

used a western blot method. As a result, pretreatment with HG activated the phosphorylation of AKT and reduced the phosphorylation of AMPK and PI3K (Fig. 6a, b). However, baicalin and wogonoside blunted the HGinduced reduction of AMPK and PI3K phosphorylation.

Table 4 Positive result of surface plasmon resonance

\begin{tabular}{llll}
\hline Molecule & Protein & Libdockscore & Kd $(\boldsymbol{\mu M})$ \\
\hline baicalin & SIRT1 & 165.299 & 214.7 \\
& HMGCR & 144.197 & 129.2 \\
& JAK3 & 146.95 & 185.7 \\
wogonoside & HNF4A & 135.677 & 713.5 \\
& SIRT1 & 154.565 & 178.7 \\
& HMGCR & 144.063 & 4.523 \\
& JAK3 & 134.219 & 4.072 \\
& HNF4A & 110.173 & 0.5545 \\
\hline
\end{tabular}

They also activated the expression of p-AKT directly, as shown in Fig. 6c, d.

\section{Discussion}

$\mathrm{DN}$, a diabetic complication, has become a worldwide challenge due to the lack of an effective treatment. Increased proteinuria is a typical clinical manifestation of DN and is mostly due to the damage of podocytes [20]. Podocytes are specialized epithelial cells that are present in the lateral glomerular basement membrane and retain the integrity of the glomerular filtration barrier [21]. Podocytes may be an important cell for DN research. In $\mathrm{DN}$, unbalanced glucose metabolism causes abnormal expression of protein kinase $\mathrm{C}$-alpha and mediates the reduction of nephrin in podocytes [22]. Moreover, HG may modulate matrix-related cell adhesion and integrin subunit synthesis, thereby affecting changes in podocyte and glomerular basement membrane interactions [23]. 


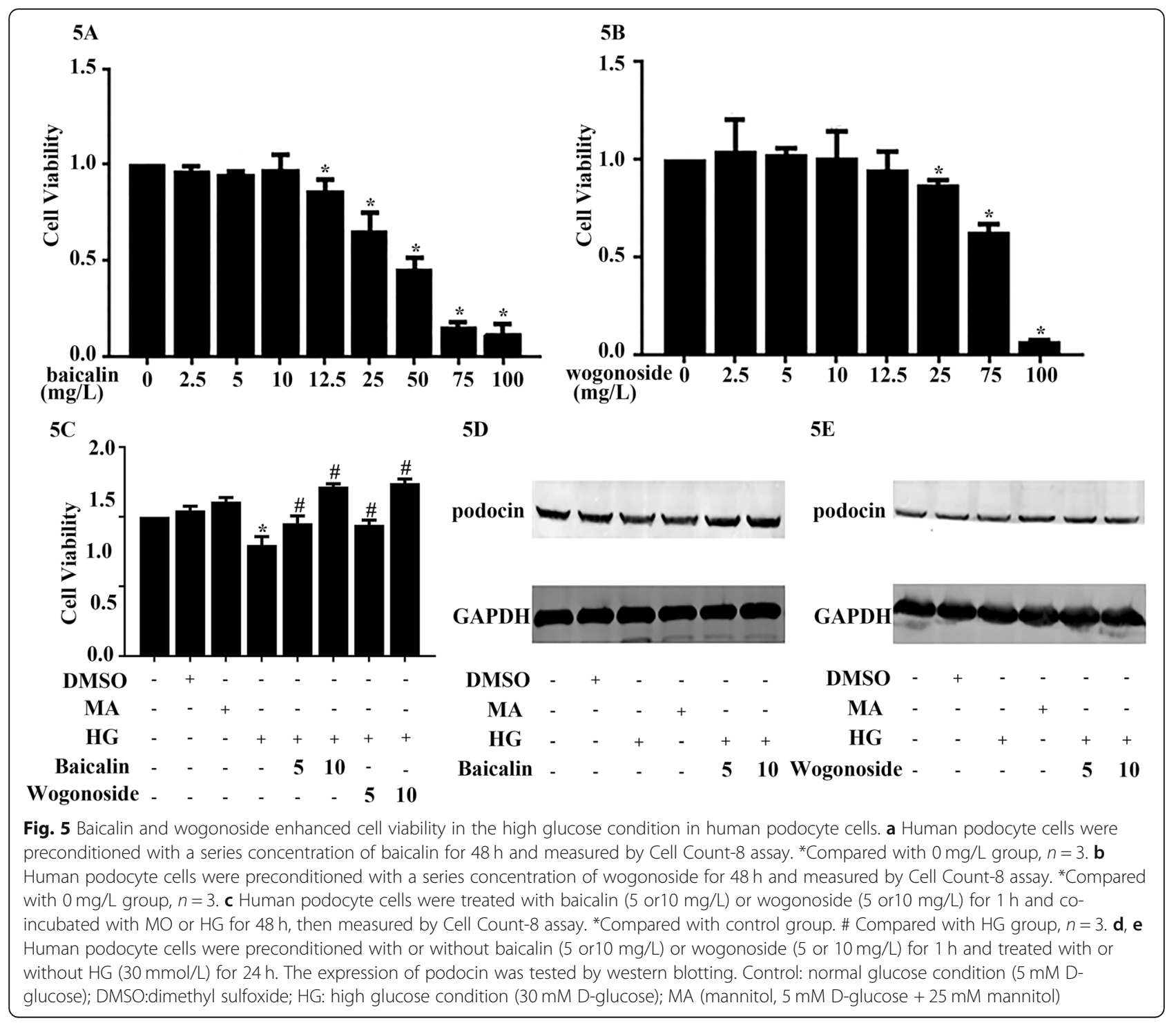

Under the pressure of HG, progressive podocyte injury continues and leads to the degeneration of podocyte foot processes, cell apoptosis, and loss of proteins [24].

The GDC may aid proteinuria reduction in combination with common treatments and has been used as a DN therapy for many years in China. However, to date, the pharmacological mechanism of GDC has not been defined due to the complex composition of compounds. Here, we used the methods of UHPLC-QQQ-MS/MS and network pharmacology to uncover the potential active compounds in GDC and preliminarily demonstrate the results in vitro. In our study, we built a molecular database including six compounds that could be absorbed into the blood of rata according to UHPLCQQQ-MS/MS. A target database was also built. Molecular docking, KEGG enrichment analysis, and network analysis were performed and four notable targets,
HNF4A, HMGCR, JAK3, and SIRT1, were observed. The binding relationship of molecules and these four targets were demonstrated via SPR. Finally, based on the result above, baicalin and wogonoside plobablely the active ingredients in GDC. And they might act via PI3K-AKT and AMPK signaling pathways. It also was observed that baicalin and wogonoside alleviated HG-induced decreased cell viability, protein marker podocin damage and adjust the protein expression of PI3K-AKT and AMPK signaling pathways in human podocyte cells.

Baicalin is a plant-derived flavonoid that has a potential antidiabetic effect [25]. Baicalin protects kidney epithelial cells against methylglyoxal-induced cytotoxicity via anti-inflammatory and antioxidant processes [26]. Baicalin can also reduce mitochondrial damage in streptozotocin-induced diabetic rats [27]. Meanwhile, 


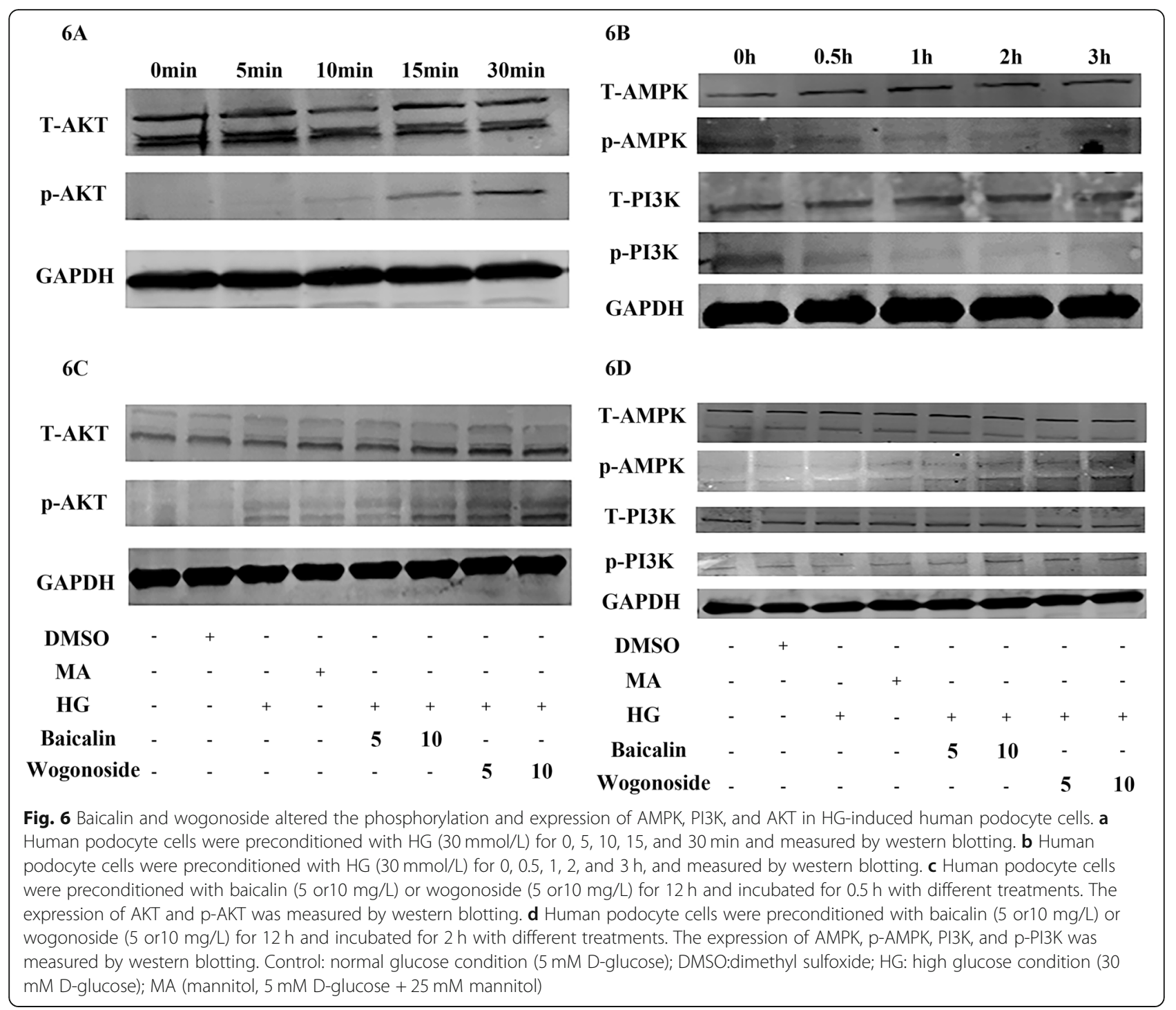

wogonoside has anti-dyslipidemia, anti-obesity, and antidiabetic effects as a traditional Chinese medicine prescription [28]. Obviously, as we know, baicalin and wogonoside had protective action in DN progress.

And in SPR test, to our knowledge, four protein targets act on the progress of DN. HNF4A is a transcription factor that regulates glucose metabolism and nutrient-induced insulin secretion in pancreatic $\beta$-cells in mice [29]. It can also inhibit vascular endothelial growth factor (VEGF)-mediated endothelial proliferation and migration and reduce VEGF-stimulated in vitro angiogenesis by directly repressing the transcript of FLK1 [30], which is closely correlated to the occurrence of DN. HMGCR is a therapeutic target and key enzyme in lipid metabolism [31]. Moreover, HMGCR inhibition, such as by atorvastatin [32], is one of the routine medicines for DN and can alleviate vascular oxidative stress [33]. JAK3 is an important molecular target for the treatment of autoimmune insulin-dependent (type 1) diabetes mellitus [34]. As a member of the JAK family, it also participates in the tyrosine-protein kinase Janus kinase /signal transducer and activator of transcription (JAK/STAT) pathway. The JAK/STAT pathway is involved in glucose metabolism [35] and T cell-reduced immune function [36]. SIRT1 has been shown to connect to $\beta$ cell function in insulin secretion in vivo [37]. Moreover, some studies indicate that SIRT1 can alleviate diabetic albuminuria in DN and SIRT1 expression can be an early sign of DN [38]. In our study, the SPR test results indicated a correlation between baicalin and wogonoside with HNF4A, HMGCR, JAK3, and SIRT1 and DN, it might be the basis of baicalin and wogonoside's protective action for cell damage in HG-induced podocyte cells.

Considering the pathways discovered to be involved in this research, PI3K-AKT and AMPK signaling pathways have a wide range of functions in the progress of $\mathrm{DN}$. 
These pathways can be activated by advanced glycation end products, which play a central role in the disease pathophysiology of DN [39]. The activation of pathways can alter a series of physiological activities to counteract disease progress. For example, regarding the PI3K-AKT signaling pathway, a study demonstrated that PI3K-AKT mediates the inhibitory effects of oxidative stress and inflammation in chronic kidney disease [40]. Another study suggested that the PI3K-AKT pathway is involved in HG-induced autophagy and apoptosis in human proximal tubular epithelial cells [41]. The targets in the AMPK signaling pathway, especially AMPK, are also involved in the protection of mitochondrial function in diabetic microvascular complications [42], such as DN. Additionally, AMPK participates in podocyte cell apoptosis as an upstream protein that regulates the mammalian target of rapamycin complex 1 [43]. As a preliminary study, our research showed the adjustment of baicalin and wogonoside in PI3K-AKT and AMPK signaling pathways. However, it still need a further study to find how drugs act through these two pathways.

In conclusion, baicalin and wogonoside may protect HG-induced podocytes against damage by influencing the AMPK and PI3K-AKT signaling pathways via binding with HNF4A, HMGCR, JAK3, and SIRT1. This study can be used to elucidate the mechanism of action of $\mathrm{GDC}$ for DN in future research.

\section{Conclusion}

In this study, six compounds in GDC were identified using a standard comparison method via UHPLC-QQQ-MS/ MS. After docking, enrichment analysis and network analysis, 11 compound-target pairs were selected to SPR. The results suggested that baicalin and wogonoside bound with HNF4A, HMGCR, JAK3, and SIRT1. Moreover, baicalin and wogonoside prevented HG-induced decreased cell viability and podocin reduction in podocytes. They also altered the phosphorylation of AMPK, PI3K, and AKT. Therefore, the influence of baicalin and wogonoside in PI3K-AKT and AMPK signaling pathways by binding with HNF4A, HMGCR, JAK3, and SIRT1 may be one of the aspects involved in the mechanism of action of GDC for the treatment of DN. This study can be used to inform future mechanistic research into GDC, DN, and other TCM.

\section{Supplementary Information}

The online version contains supplementary material available at https://doi. org/10.1186/s12906-020-03155-4.

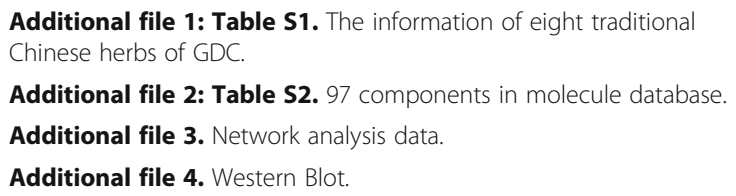

\section{Abbreviations}

DN: Diabetic nephrophy; SGLT-2: Sodium-dependent glucose transporter 2; ACEl: Angiotensin-converting enzyme inhibitor; GDC: Gandi capsule; TCM: Traditional Chinese medicine; eGFR: Estimated glomerular filtration rate; SPR: Surface plasmon resonance; SD: Sprague Dawley; PI3K: Phosphoinositide 3-kinase; AKT: Protein kinase B; AMPK: 5' AMP-activated protein kinase; HNF4A: Hepatocyte nuclear factor 4-alpha; HMGCR: 3-hydroxy-3methylglutaryl-coenzyme A reductase; JAK3: Tyrosine-protein kinase Janus kinase 3; SIRT1: NAD-dependent protein deacetylase sirtuin-1; CUR: Curtain; CAD: Collision activation dissociation; MRM: Multiple reaction monitoring; DP: Declustering potential; EP: Entrance potential; CE: Collision energy; CXP: Collision cell exit potentials; OB: Oral bioavailability; DL: Drug-likeness; TTD: Therapeutic Target Database; GEO: Gene Expression Omnibus; logFC: Log fold change; KEGG: Kyoto Encyclopedia of Genes and Genomes; NC: Neighborhood Connectivity; RPMI: Roswell Park Memorial Institute; FBS: Fetal bovine serum; CCK-8: Cell counting kit-8; HG: High glucose; MA: Mannitol; DMSO: Dimethyl sulfoxide; TBST: $1 \times$ Tris-buffered saline and 0.1\% Tween 20; VEGF: Vascular endothelial growth factor; STAT: Signal transducer and activator of transcription

\section{Acknowledgments}

Not applicable.

\section{Authors' contributions}

JZ identified the problem and proposed the study. JZ, HZ, QZ designed the protocol and carried out experimentation. $\mathrm{XH}$ performed the experiment about UHPLC-QQQ-MS/MS. QZ and QY conducted experiments for SPR and in-vitro cell line study. JZ, HZ, QZ finished this manuscript and AJ, YL, JQ revised this article. All authors read and approved the manuscript for publication.

\section{Funding}

The research was supported by the Science and Technology Commission of Shanghai Municipality [No. 16401900500, No. 19401900500]. The funder has no role/influence in this study.

\section{Availability of data and materials}

The datasets used and/or analyzed during the current study are available from the corresponding author on reasonable request.

\section{Ethics approval}

The presented research work involves the use of SD rats and the experimental protocol was duly approved from the ethics committee of Shanghai Jiaotong University School of Medicine (Shanghai, China), NO. SYXK (Shanghai) 2018-0038. All animals purchase from Shanghai SLAC Laboratory Animal Co.,Ltd. (Shanghai, China), SCXK (Shangahi) 2017-0005 and were fed in a SPF environment in the Laboratory Animal Center of Xinhua Hospital affiliated to Shanghai Jiaotong University School of Medicine.

\section{Consent for publication}

Not applicable.

\section{Competing interests}

No conflict of interest exists in the submission of this manuscript and the manuscript is approved by all authors for publication.

Received: 4 February 2020 Accepted: 10 November 2020 Published online: 23 November 2020

\section{References}

1. Saran R, Robinson B, Abbott KC, Agodoa LY, Albertus P, Ayanian J, Balkrishnan R, Bragg-Gresham J, Cao J, Chen JL, et al. US renal data system 2016 annual data report: epidemiology of kidney disease in the United States. Am J Kidney Dis. 2017;69(3 Suppl 1):A7-a8.

2. Collins AJ, Foley RN, Chavers B, Gilbertson D, Herzog C, Ishani A, Johansen K, Kasiske BL, Kutner N, Liu J, et al. US Renal Data System 2013 Annual Data Report. Am J Kidney Dis. 2014;63(1 Suppl):A7.

3. Heerspink HJL, Parving HH, Andress DL, Bakris G, Correa-Rotter R, Hou FF, Kitzman DW, Kohan D, Makino H, McMurray JJV, et al. Atrasentan and renal events in patients with type 2 diabetes and chronic kidney disease (SONAR): 
a double-blind, randomised, placebo-controlled trial. Lancet. 2019; 393(10184):1937-47.

4. Z Zhang L, Long J, Jiang W, Shi Y, He X, Zhou Z, Li Y, Yeung RO, Wang J, Matsushita K, et al. Trends in chronic kidney disease in China. N Engl J Med. 2016;375(9):905-6.

5. Lo C, Toyama T, Wang Y, Lin J, Hirakawa Y, Jun M, Cass A, Hawley CM, Pilmore $\mathrm{H}$, Badve SV, et al. Insulin and glucose-lowering agents for treating people with diabetes and chronic kidney disease. Cochrane Database Syst Rev. 2018:9:Cd011798.

6. Anders HJ, Huber TB, Isermann B, Schiffer M. CKD in diabetes: diabetic kidney disease versus nondiabetic kidney disease. Nat Rev Nephrol. 2018; 14(6):361-77.

7. Pofi R, Di Mario F, Gigante A, Rosato E, Isidori AM, Amoroso A, Cianci R, Barbano B. Diabetic nephropathy: focus on current and future therapeutic strategies. Curr Drug Metab. 2016;17(5):497-502.

8. Husain M, Birkenfeld AL, Donsmark M, Dungan K, Eliaschewitz FG, Franco DR, Jeppesen OK, Lingvay I, Mosenzon O, Pedersen SD, et al. Oral Semaglutide and cardiovascular outcomes in patients with type 2 diabetes. N Engl J Med. 2019;381(9):841-51.

9. Parving $\mathrm{HH}$, Lambers-Heerspink $\mathrm{H}$, de Zeeuw D. Empagliflozin and progression of kidney disease in type 2 diabetes. N Engl J Med. 2016; 375(18):1800-1.

10. Wei $X$, Huang Z, Zhang L. Therapeutic efficacy and safety of Gandi capsules combined with routine treatment for diabetic nephropathy and its effects on related indicators. China Pharmacy. 2018;29(22):3134-8.

11. Liu Y, Chen X, Liu Y, Chen T, Zhang Q, Zhang H, Zhu Z, Chai Y, Zhang J. Metabolomic study of the protective effect of Gandi capsule for diabetic nephropathy. Chem Biol Interact. 2019;314:108815.

12. Zhang J, Liu Y, Chen T, Huang X, Zhang H, Chen X, Zhang Q, Tang Y, Chen $W$, Chai $Y$. Assessment of the Intestinal Permeability of Major Phytocomponents Contained in Gandi Capsules Using Ultra-High Performance Liquid Chromatography Coupled with Electrospray IonizationQuadrupole-Time of Flight Mass Spectrometry. Chromatographia. 2018;81(7): 1013-21.

13. Hopkins AL. Network pharmacology: the next paradigm in drug discovery. Nat Chem Biol. 2008;4(11):682-90

14. da Hao C, Xiao PG. Network pharmacology: a Rosetta stone for traditional Chinese medicine. Drug Dev Res. 2014;75(5):299-312

15. Li S, Zhang B. Traditional Chinese medicine network pharmacology: theory, methodology and application. Chin J Nat Med. 2013:11(2):110-20.

16. Dong Y, Qiu P, Zhu R, Zhao L, Zhang P, Wang Y, Li C, Chai K, Shou D, Zhao $\mathrm{H}$. A combined Phytochemistry and network pharmacology approach to reveal the potential antitumor effective substances and mechanism of Phellinus igniarius. Front Pharmacol. 2019;10:266.

17. Wu CW, Lu L, Liang SW, Chen C. Wang SM: [application of drug-target prediction technology in network pharmacology of traditional Chinese medicine]. Zhongguo Zhong Yao Za Zhi. 2016;41(3):377-82.

18. Nguyen HH, Park J, Kang S, Kim M. Surface plasmon resonance: a versatile technique for biosensor applications. Sensors (Basel). 2015;15(5):10481-510.

19. Saleem MA, O'Hare MJ, Reiser J, Coward RJ, Inward CD, Farren T, Xing CY, Ni L, Mathieson PW, Mundel P. A conditionally immortalized human podocyte cell line demonstrating nephrin and podocin expression. J Am Soc Nephrol. 2002;13(3):630-8.

20. Lee SY, Choi ME. Urinary biomarkers for early diabetic nephropathy: beyond albuminuria. Pediatr Nephrol. 2015;30(7):1063-75.

21. Tung CW, Hsu YC, Shih YH, Chang PJ, Lin CL. Glomerular mesangial cell and podocyte injuries in diabetic nephropathy. Nephrology (Carlton). 2018; 23(Suppl 4):32-7.

22. Tossidou I, Starker G, Kruger J, Meier M, Leitges M, Haller H, Schiffer M. PKCalpha modulates TGF-beta signaling and impairs podocyte survival. Cell Physiol Biochem. 2009;24(5-6):627-34.

23. Hu C, Sun L, Xiao L, Han Y, Fu X, Xiong X, Xu X, Liu Y, Yang S, Liu F, et al. Insights into the mechanisms involved in the expression and regulation of extracellular matrix proteins in diabetic nephropathy. Curr Med Chem. 2015; 22(24):2858-70.

24. Zhang MZ, Sasaki K, Li Y, Li Z, Pan Y, Jin GN, Wang Y, Niu A, Wang S, Fan X, et al. The role of the EGF receptor in sex differences in kidney injury. J Am Soc Nephrol. 2019;30(9):1659-73.

25. Xiao J, Muzashvili TS, Georgiev MI. Advances in the biotechnological glycosylation of valuable flavonoids. Biotechnol Adv. 2014;32(6):1145-56.
26. Singh J, Chaudhari BP, Kakkar P. Baicalin and chrysin mixture imparts cytoprotection against methylglyoxal induced cytotoxicity and diabetic tubular injury by modulating RAGE, oxidative stress and inflammation. Environ Toxicol Pharmacol. 2017:50:67-75.

27. Waisundara VY, Hsu A, Tan BK, Huang D. Baicalin reduces mitochondrial damage in streptozotocin-induced diabetic Wistar rats. Diabetes Metab Res Rev. 2009;25(7):671-7.

28. Han K, Bose S, Wang JH, Lim SK, Chin YW, Kim YM, Choi HS, Kim H. In vivo therapeutic effect of combination treatment with metformin and Scutellaria baicalensis on maintaining bile acid homeostasis. PLoS One. 2017;12(9): e0182467.

29. Wang H, Maechler P, Antinozzi PA, Hagenfeldt KA, Wollheim CB. Hepatocyte nuclear factor 4alpha regulates the expression of pancreatic beta -cell genes implicated in glucose metabolism and nutrient-induced insulin secretion. J Biol Chem. 2000;275(46):35953-9.

30. Chai X, Yan J, Gao Y, Jin J. Endothelial HNF4alpha potentiates angiogenic dysfunction via enhancement of vascular endothelial growth factor resistance in T2DM. J Cell Biochem. 2019;120(8):12989-3000.

31. Takei A, Nagashima S, Takei S, Yamamuro D, Murakami A, Wakabayashi T, Isoda M, Yamazaki H, Ebihara C, Takahashi M, et al. Myeloid HMG-CoA (3hydroxy-3-methylglutaryl-coenzyme a) Reductase determines adipose tissue inflammation, Insulin Resistance And Hepatic Steatosis In Diet-Induced Obese Mice. Diabetes. 2020;69(2):158-64.

32. Pignatelli $P$, Carnevale R, Pastori D, Cangemi R, Napoleone L, Bartimoccia S, Nocella C, Basili S, Violi F. Immediate antioxidant and antiplatelet effect of atorvastatin via inhibition of Nox2. Circulation. 2012;126(1):92-103.

33. Forstermann $U$, Sessa WC. Nitric oxide synthases: regulation and function. Eur Heart J. 2012;33(7):829-837, 837a-837d.

34. Cetkovic-Cvrlje M, Dragt AL, Vassilev A, Liu XP, Uckun FM. Targeting JAK3 with JANEX-1 for prevention of autoimmune type 1 diabetes in NOD mice. Clin Immunol. 2003:106(3):213-25.

35. Krolopp JE, Thornton SM, Abbott MJ. IL-15 activates the Jak3/STAT3 signaling pathway to mediate glucose uptake in skeletal muscle cells. Front Physiol. 2016;7:626.

36. Stabile H, Scarno G, Fionda C, Gismondi A, Santoni A, Gadina M, Sciume G. JAKVSTAT signaling in regulation of innate lymphoid cells: the gods before the guardians. Immunol Rev. 2018:286(1):148-59.

37. Moynihan KA, Grimm AA, Plueger MM, Bernal-Mizrachi E, Ford E, CrasMeneur C, Permutt MA, Imai S. Increased dosage of mammalian Sir2 in pancreatic beta cells enhances glucose-stimulated insulin secretion in mice. Cell Metab. 2005;2(2):105-17.

38. Bible E. Diabetic nephropathy: Sirt1 attenuates diabetic albuminuria. Nat Rev Nephrol. 2013;9(12):696.

39. Sanajou D, Ghorbani Haghjo A, Argani H, Aslani S. AGE-RAGE axis blockade in diabetic nephropathy: current status and future directions. Eur J Pharmacol. 2018:833:158-64.

40. Wang D, Jin M, Zhao X, Zhao T, Lin W, He Z, Fan M, Jin W, Zhou J, Jin L, et al. FGF1(DeltaHBS) ameliorates chronic kidney disease via PI3K/AKT mediated suppression of oxidative stress and inflammation. Cell Death Dis. 2019;10(6):464.

41. Chen F, Sun Z, Zhu X, Ma Y. Astilbin inhibits high glucose-induced autophagy and apoptosis through the PI3K/Akt pathway in human proximal tubular epithelial cells. Biomed Pharmacother. 2018;106:1175-81.

42. Dugan LL, You YH, Ali SS, Diamond-Stanic M, Miyamoto S, DeCleves AE, Andreyev A, Quach T, Ly S, Shekhtman G, et al. AMPK dysregulation promotes diabetes-related reduction of superoxide and mitochondrial function. J Clin Invest. 2013;123(11):4888-99.

43. Szrejder M, Piwkowska A. AMPK signalling: implications for podocyte biology in diabetic nephropathy. Biol Cell. 2019;111(5):109-20.

\section{Publisher's Note}

Springer Nature remains neutral with regard to jurisdictional claims in published maps and institutional affiliations. 